\title{
Antonio Candido ou direito à poesia
}

\author{
Waltencir Alves de Oliveira*
}

\section{RESUMO}

O artigo analisa o livro Na sala de aula: caderno de análise literária, de Antonio Candido, situando-o no contexto amplo da obra crítica, teórica e historiográfica do autor. "O caderno", como o denomina o próprio Candido, foi apresentado em sua primeira edição como uma coletânea de exercícios críticos de análise de poesia. É transcrição quase fiel de um conjunto de seis ensaios analíticos apresentados em um curso de pósgraduação, ministrado pelo professor. A alusão à sala de aula, desde o título da obra, explicita o vínculo estreito entre o professor e o crítico. O que se pretende discutir é como o modelo analítico empregado e como a própria seleção e ordenação dos poemas analisados desvelam, ainda que de forma implícita, a vinculação estreita entre a atividade crítica e todo o conjunto da obra teórico-historiográfica de Antonio Candido. A hipótese que se pretende verificar é como na análise de poesia, Antonio Candido deixa antever os mesmos pressupostos que nortearam todo o conjunto de sua obra.

Palavras-chave: Antonio Candido. Crítica literária brasileira. Historiografia literária. Estudo analítico do poema. Literatura e sociedade.

* Professor adjunto de Teoria Literária e Literatura Brasileira do Departamento de Linguística e Literatura (DELLIN), da Universidade Federal do Paraná. Doutor em Teoria Literária e Literatura Comparada pelo DTLLC/ USP. 


\section{Antonio Candido ou du droit à la poésie}

\section{ABSTRACT}

Cet article fait l' anályse du livre Na sala de aula: caderno de análise literária, par Antonio Candido, le situer dans le contexte large de sa oeuvre critique, théorique et historiographiquel. Le cahier, comme le nom de Candide lui-même, a été présenté dans sa première édition comme une collection d'exercices critiques de l'analyse de la poésie. Transcription presque fidèle d'un ensemble de six essais analytiques présentés dans un cours de troisième cycle, enseigné par le professeur. L'allusion à la salle de classe, du titre de l'œuvre, explique le lien étroit entre l'enseignant et le critique. Ce qui est destiné à être discuté, c'est comment le modèle analytique employé et la sélection et l'ordination des poèmes analysés ont dévoilé, quoique implicitément, le lien étroit entre l'activité critique et l'ensemble du travail théorique-historiographique d'Antonio Candido. L'hypothèse qui est censée être vérifiée est comme dans l'analyse de la poésie, Antonio Candido les mêmes hypothèses qui ont guidé l'ensemble de son travail ont été anticipées.

Mots-clés: Antonio Candido. Critique littéraire brésilienne. Historiographie littéraire. Etude analytique du poème. La littérature et la société. 
Antonio Candido inicia sua atuação como crítico literário na Revista Clima, fundada e mantida durante os anos de 1941 e 1942, por ele, Décio de Almeida Prado, Paulo Emílio Salles Gomes entre outros; logo em seguida, dá início à publicação de ensaios críticos na forma então usual da crítica sistemática de rodapé, ${ }^{1}$ em jornais como Folha da Manhã (1943-1945) e Diário de São Paulo (1945-1947), sem contar a participação em outros jornais e revistas da época. É interessante mencionar que, apesar do caráter da crítica jornalística da época (predominantemente dirigida a discutir e avaliar textos literários), Vinícius Dantas, em sua seleção nos jornais da época para integrar os Textos de Intervenção (CANDIDO, 2002), reúne alguns artigos nos quais Candido discute a função do crítico e a natureza da atividade, apresentando o que poderíamos denominar uma "metacrítica". Textos datados do início dos anos 40, mas que antecipam muitos pressupostos depois explicitados pelo autor na definição de um método analítico-interpretativo, sobre o qual se assentará a obra historiográfica-teórica-crítica que Candido produzirá no decorrer das décadas seguintes, já no exercício de sua atividade acadêmica na universidade. É o caso, por exemplo, de um artigo publicado em 9 de novembro de 1944, no jornal Folha da manhã, no qual Candido expõe a perspectiva que lhe parece adequada ao trabalho do crítico com o texto literário:

Tenho sobretudo a alegria de achar que vou mais ou menos cumprindo o meu intento de chamar a atenção do leitor para aspectos pouco lembrados pela nossa crítica

1 Deve-se lembrar que, por essa época, Antonio Candido escreveu importantes textos de crítica literária, como a análise inaugural sobre a prosa de Clarice Lispector, Perto do Coração Selvagem, em 16 de julho de 1944, na Folha da Manhã; a primeira crítica sobre a poesia de João Cabral de Melo Neto, "Poesia ao Norte", no mesmo jornal, em 16 de junho de 1943 e vários outros artigos em que inaugura e orienta a crítica sobre os mais importantes autores brasileiros. 
literária, quais sejam o sentido e o condicionamento histórico-social da criação e da obra de arte (CANDIDO, 2002, p. 32).

Pode-se dizer que, apesar do caráter ainda incipiente que suas primeiras intervenções críticas poderiam ter, elas já se apresentavam fundadas sobre um programa que afirmava o caráter estético da literatura e sua dimensão social e histórica. Deve-se ressaltar o termo empregado para tratar da relação entre o texto e o seu contexto: segundo o autor, há um "condicionamento", divergindo da ideia de que a literatura e a arte seriam como reflexos do social e do histórico, conforme a nota dominante de uma certa crítica de inspiração sociológica da época. Antonio Candido já aponta que há uma relação entre literatura e sociedade que seria melhor caracterizada como condicionamento de um pelo outro. Isso evidencia a originalidade de seu trabalho crítico em um cenário que, ou bem encarava o literário como espaço de espelhamento e reflexo, sem atenuantes, do social e histórico, ou, em posição diametralmente antagônica, afirmava a autonomia do literário e a completa dissociação entre análise estético-linguística e perspectiva social e histórica. Ou bem um reducionismo sociologizante, ou um "descritivismo formalista" que não atentava para as implicações do sujeito e da História no corpo do texto. Sem contar, obviamente, a sobrevivência, talvez até mesmo nos dias atuais, de certa crítica impressionista assentada na valoração pura e simplesmente guiada pelos critérios do "gosto", portanto desprovidas de qualquer rigor técnico ou metodológico.

Sabe-se que a atuação universitária de Antonio Candido, durante a década de 40, concentrou-se em sua área de formação, as Ciências Sociais. Por esse período, atuou como professor 
assistente de Fernando Azevedo, na cadeira de Sociologia I, da Faculdade de Filosofia, Letras e Ciências Humanas da Universidade de São Paulo. A primeira tentativa de ingresso na área de Letras se dá em 1957, ao participar de um concurso para o departamento de Literatura Brasileira da mesma faculdade. Embora não tenha obtido a vaga, resultou dela a tese defendida para sua obtenção, que lhe garantiu o título de livre-docente. Surge então sua primeira obra dedicada especificamente à área de Letras: O método crítico de Sílvio Romero. O ingresso na carreira de professor de Literatura Brasileira se dá em 1958, ano em que começa a atuar na Faculdade de Filosofia e Letras de Assis. No ano seguinte, já ocorre a publicação do livro Formação da literatura brasileira: momentos decisivos, em que se postula a existência de uma vinculação estreita e indissociável entre as várias áreas em que, tradicionalmente, são divididos os estudos literários. O livro apresenta sobre cada texto literário e sobre cada autor estudado uma análise crítica rigorosa e detida, norteada por um método original para a época. A atividade crítica não exclui a formulação de um método teórico e historiográfico que, ao mesmo tempo, regula as análises críticas ali contidas, constituindo uma teoria não só da literatura, como da literatura brasileira especificamente, estabelecendo parâmetros não só para os modelos teóricos, para a atividade crítica, mas, sobretudo, para os modelos que a historiografia literária brasileira conhecia até então.

Alfredo Bosi aponta que a historiografia literária brasileira pode se dizer inaugurada pela concepção nacionalista de Sílvio Romero e Araripe Jr. e pela visão estetizante de José Veríssimo. Desse ponto, passou pelo ecletismo da crítica modernista de Mário de Andrade e de Tristão de Athayde até que chega às 
sínteses explicativas de Antonio Candido e de Otto Maria Carpeaux. Na visão de Bosi, Carpeaux e Candido lançam as bases de um novo modelo historiográfico, que aponta as grandes tendências existenciais e culturais configuradas na concepção de estilo de época, mas que também confronta cada obra específica, constatando que cada uma delas é espaço tenso e particular em que o estilo poderá sofrer redimensionamentos e até mesmo o apagamento de muitos de seus parâmetros. Alfredo Bosi adverte que a "procura de esquemas uniformes de método no discurso crítico de Antonio Candido nem sempre é o melhor caminho para avaliar a riqueza surpreendente de sua obra" (BOSI, 2000, p. 40), contudo admite que a noção de historiografia, entendida como a complexa relação de reconstruir o particular no geral, e vice-versa, sempre se faz presente em toda a produção de Antonio Candido, embora seja variável e diversa a matéria sobre a qual ele se debruça, e variável o modo como o método se aplica e se ajusta ao objeto.

A multiplicidade de canais de veiculação da crítica, a definitiva incorporação da leitura crítica de textos literários pela instituição universitária, a delimitação teórica de um método próprio de leitura, análise e interpretação da Literatura constituem algumas das contribuições significativas de Antonio Candido para o cenário dos Estudos Literários no Brasil. Com Formação da literatura brasileira: momentos decisivos, o autor dá mais um passo decisivo para a maturidade do cenário crítico e teórico. Nela se fixa um modelo de historiografia literária cujos parâmetros de historicização e análise da produção cultural nacional são remodelados. Com isso, refuta-se o historicismo positivista e fundam-se novos modelos de análise e interpretação. $\mathrm{O}$ elenco de obras e autores dispostos em uma linha evolutiva e linear é 
substituído pela leitura pontual e efetiva dos textos literários em sua singularidade e especificidade, concebendo entre particular (obra e autor) e geral (período literário) uma circularidade.

O método de análise crítica-historiográfica empregado em Formação da Literatura Brasileira sofreu algumas sutis e importantes redefinições na produção posterior de Antonio Candido. É o que se pode afirmar, consultando alguns livros e textos seus, tais como: Literatura e sociedade (1965); "Literatura de dois gumes" (1966/1969); "Dialética da malandragem" (1970) e "Literatura e subdesenvolvimento" (1972/1973). Nesses textos posteriores, pode-se compreender que a compreensão de nossa "lei de evolução espiritual e cultural", qual seja "a síntese, mais ou menos tensa, entre localismo e universalismo" (CANDIDO, 1965 , p. 45), sofre alterações significativas que, embora o escopo deste artigo não permita detalhar, é preciso pontuar, para efeito de compreender a complexidade de uma obra que nunca deveria ser avaliada em função de uma única obra, ou de um só "galho da árvore".

A importância que Formação da literatura brasileira possui para o estabelecimento de um novo modelo historiográfico já constitui matéria bastante discutida, e por vezes, controversa. Neste artigo, o que se pretende é abordar de que modo o método crítico-analítico formulado nesse livro, assume feição paradigmática, modulando a atividade crítica exercida por Antonio Candido no decorrer das décadas seguintes à publicação do livro de 1959. Com base nisso, é que pretendo refletir sobre o livro Na sala de aula: caderno de análises literárias, visando a observar como se articulam nele, ainda que de modo não explícito, alguns pressupostos teóricos-historiográficos, anteriormente formulados. Esses pressupostos, ao que me parece, 
converteram-se em princípio ordenador das leituras dos poemas, deixando antever que as análises, aparentemente isoladas entre si, estão agrupadas em torno de uma concepção específica de poesia e de crítica de poesia que jamais as apartaria da visada historiográfica - muitas vezes não claramente explicitada, mas, ainda assim, verificável.

O método teórico-historiográfico esboçado em Formação da literatura brasileira foi explicitado no livro Literatura e sociedade, de 1965, no qual se pode encontrar a sua clássica formulação de que a crítica do texto literário corresponderia, entre outras coisas, a estabelecer a correlação entre "elementos externos que se tornam internos e estruturadores da obra literária, portanto estéticos". (CANDIDO, 1965, p. 8). No que se refere, especificamente, à leitura de poesia, o método analítico de Antonio Candido aparece definido em seu O Estudo Analítico do Poema, cuja primeira edição data de 1987. Na apresentação desse livro, é o próprio Candido que adverte que ele é resultado de um material escrito para uma disciplina sobre leitura de poesia ministrada por ele, em 1964, no programa de pós-graduação do Departamento de Teoria Literária e Literatura Comparada, da FFLCH- USP. Ou seja, o livro é publicado na década de 80, mas é possível afirmar que as análises literárias de poesia que o crítico fez, ao menos as do período posterior à disciplina ministrada na década de 60 , foram calcadas sobre o método analítico detalhado nesse livro. Dois anos antes, 1985, já havia sido publicado o livro Na sala de aula: caderno de análises literárias, oriundo dessa mesma matriz, a mesma disciplina ministrada em "sala de aula" pelo professor Antonio Candido. Sendo assim, há entre os dois volumes uma mesma origem, mas, mais que isso, há uma complementaridade entre eles. Em um, explicita-se e discute-se 
um método e, em outro, há como que a instrumentalização e emprego efetivo dele. Os vários modos como se dá a aplicação desse método na leitura analítica de seis poemas não é passível de simplificações. Aqui, contudo, o que se pretende é enfatizar como, no exercício de análise de poesia e na fixação do método que regula essa prática (ambas, práticas em seu sentido pleno, já que exercitadas em aulas efetivas de um curso), também desponta o modelo historiográfico-teórico aplicado em Formação... e explicitado em Literatura e sociedade. Isso me parece reiterar a principal característica que marca a ação e o trabalho de Antonio Candido como crítico, como professor, e que também transparece na dimensão política com que ele exerce essas duas atividades, que seria a extrema coerência entre toda atividade crítica e a presença de um mecanismo integrador que torna todas as obras e ações partes integrantes de uma mesma atuação empenhada, militante e coesa.

Isso é o que se pretende demonstrar ao tratar do livro Na sala de aula, apontando nele a presença de pressupostos analíticos oriundos do método historiográfico que ordena Formação da literatura brasileira, de 1959. É interessante observar, aliás, o que é indicado no prefácio do próprio livro Na sala de aula:

Este caderno contém seis análises de poemas, que procuram sugerir ao professor e ao estudante maneiras possíveis de trabalhar o texto, partindo da noção de que cada um requer tratamento adequado à sua natureza, embora com base em pressupostos teóricos comuns. Um destes pressupostos é que os significados são complexos e oscilantes. Outro, que o texto é uma espécie de fórmula, onde o autor combina consciente ou inconscientemente elementos de vário tipo. Por isso, na medida em que se estrutura, isto é são reelaborados numa síntese própria, estes elementos só podem ser considerados externos ou internos para facilidade de expressão. (CANDIDO, 1987, p. 7-8). 
É esclarecedora a fórmula sintetizada do seu método analítico no prefácio desse livro - "pequeno" diante das feições hercúleas de outros como Formação.... A combinação, síntese ou tensão intermitente, entre procedimentos e métodos, até então díspares, é clara e demonstra o caminho singular de Antonio Candido como leitor crítico da literatura brasileira. Isso parece bem explicado na síntese que Davi Arrigucci Jr. propõe ao tratar do método de leitura de Antonio Candido:

Evitando tanto o velho método histórico que fazia das obras documentos da realidade social, tratando a literatura como mero índice para a investigação sobre a sociedade, assim como o formalismo, com sua redução da literatura aos elementos de fatura, absolutizando a autonomia da obra como universo auto-suficiente, o crítico busca um enfoque o mais significativo e amplo possível do fenômeno literário. [...] uma vez que o texto é o resultado relativamente autônomo da integração entre elementos externos e internos, cujo valor reside na unidade superior que plasmou ao integrar elementos expressivos e elementos não-literários numa "fórmula" (ou numa "forma orgânica" ou "estrutura", como dirá mais tarde), que se exprime pela coerência. (ARRIGUCCI JR., 1992, p. 19).

Davi Arrigucci Jr., ao analisar os movimentos desse "leitor", explicita alguns mecanismos de leitura aludidos pelo próprio Antonio Candido no prefácio de Na sala de aula. Nessa introdução, o livro é descrito pelo autor como exemplificador de um método, um material essencialmente prático de uso instrumental de uma teoria, aplicada exclusivamente sobre textos poéticos. Ainda que a leitura se restrinja somente ao prefácio, já é possível constatar a presença de pressupostos teóricos heterogêneos, que aqui se dispõem a operar em conjunto a favor de um esforço de totalização, ainda que momentânea, de um 
objeto. Alguns desses pressupostos de leitura talvez possam ser discutidos mais claramente depois de se apresentarem as seis análises de poemas que integram o livro.

Os seis ensaios dispõem em linha evolutiva-histórica seis poemas de períodos literários diferentes. O primeiro "Movimento e parada", analisa um trecho do poema épico Caramuru, do Frei Santa Rita Durão; o segundo, "Uma aldeia falsa", trata da Lira $77^{2}$ de Tomás Antônio Gonzaga; o terceiro é o texto analítico "Cavalgada ambígua", sobre o poema "Meu sonho", de Álvares de Azevedo; a quarta resulta no ensaio "No coração do silêncio", sobre o poema "Fantástica", de Alberto de Oliveira; os dois últimos tratam de poemas modernistas: o ensaio "Carrossel", sobre o "O rondó dos cavalinhos", de Manuel Bandeira, e "Pastor pianista, pianista pastor", sobre poema de Murilo Mendes "O pastor pianista".

A linha evolutiva da lírica nacional é seguida também nesse livro. Ele se inicia com dois poemas pertencentes ao Arcadismo, movimento que, segundo Antonio Candido, em Formação da literatura brasileira, constitui o primeiro movimento de futuros brasileiros "empenhados" na constituição de uma literatura. No terceiro, a análise recai sobre um poeta romântico, período em que, segundo Candido, já podemos constatar a existência de um sistema literário, no qual autor, leitor e obra começam a compartilhar um conjunto de ideais e princípios que permitem apontar a existência de uma nação. E segue acompanhando poemas que atestam a evolução desse sentimento nativista primordial, até a superação de nossa dependência cultural em relação aos modelos europeus.

O ensaio sobre o Caramuru aponta que há na poesia épica de Santa Rita Durão motivações e princípios formais anteriores

2 Numeração segundo à edição utilizada por Candido que é a preparada por M. Rodrigues Lapa para o Instituto Nacional do Livro. 
ao período árcade, ao qual se filia o poeta. $\mathrm{Na}$ análise material do poema épico, Candido destaca a presença de princípios de composição usuais na estética do Barroco e constata o choque entre esse modelo com alguns princípios estéticos norteadores do Arcadismo/Neoclassicismo. A leitura cerrada da épica de Durão destaca o constante emprego de paradoxos e oximoros, vistos como anacronismos da "velha escola", combinados a recursos expressivos que, paradoxalmente, visam à simplicidade da expressão e à restrição de malabarismos verbais. A contradição entre velho e novo na estrutura formal do texto integra uma narrativa épica, que tem nos modelos épicos portugueses/ ibéricos seu modelo ideal de realização. Trata-se de um dos primeiros esforços, portanto, de atribuir ao indígena - e ao tema tributário nacional, o indianismo - um lugar de inserção dentro de uma estrutura formal europeia, que nunca o tinha incorporado e tematizado por motivos óbvios. A análise crítica de um fragmento de um poema épico, e não dele todo, traça um panorama dos primeiros movimentos do Arcadismo em busca de afirmar aqui as condições de existência de forma literárias europeias, combinando-as a um universo temático e a uma construção de um espaço que são locais e bem demarcados. Desse modo, poderíamos concluir que Antonio Candido vê nesse fragmento e no todo do poema épico de Santa Rita Durão um traço peculiar de todo um estágio inicial do processo de formação da literatura brasileira. A síntese (ou tensão?) entre formas e motivações temáticas díspares, contudo combinadas, dialeticamente aponta para o esforço de apropriação de formas e modelos "importados" ajustados às novas circunstâncias e motivações temáticas locais. Desvelam, portanto, o desejo ou empenho ainda incipiente de conceber a mistura de formas, 
modelos e temas de variados extratos e períodos, como uma condição de existência da literatura no Brasil. Mistura, tensão, assimilação, síntese, todas essas palavras que se podem empregar para tratar do poema de Santa Rita Durão e que são perceptíveis desde a descrição que Candido faz no comentário até a sua interpretação final ${ }^{3}$ do poema reiteram, na atividade do crítico que lê o poema, a mão invisível do historiador que analisou nosso processo histórico de constituição, ou formação, da literatura brasileira.

O segundo ensaio, "Uma aldeia falsa" apresenta a leitura da Lira 77, de Tomás Antônio Gonzaga. Desde a paráfrase, comentário que abre o ensaio analítico, já se apesenta a fórmula de desentranhar da estrutura do texto elementos que podem ser correlacionados a elementos externos que o enformaram. A lira é dividida em função do emprego de três tempos verbais diferentes, cada um bastante marcado por qualificativos que explicitam o reconhecimento de um passado glorioso, um presente degradante e um futuro condicional e hipotético de possível superação da adversidade. A constatação desse elemento integrante da fatura textual é que consente a interpretação final da lira, que convoca elementos biográficos do autor, correlacionando cada

3 Os limites deste artigo não permitem a exposição detalhada de todos os elementos constitutivos do método de análise de poesia de Candido. Não se pode deixar de mencionar, contudo, que há, nele, a divisão da leitura em três estágios, seguindo as diretrizes metodológicas da Explication $d u$ texte francesa. O próprio autor remete ao modelo francês, quando assume que as seis leituras de poemas se dividem em comentário, análise e interpretação. Não é explicitado no livro Na sala de aula - embora o seja em O estudo analítico do poema - o quanto as análises são tributárias de um "modelo circular spitizeriano", que busca detectar o desvio estilístico que seria um elemento central para compreender a totalidade do texto. Para Spitizer, a circularidade entre a parte e o todo, e seu vice-versa, seria uma reapropriação sua do círculo hermenêutico ou círculo de Schleiermacher, postulando um movimento de leitura que trafega do traço de estilo para o traço de época, e vice-versa, o que é primordial nas análises de Erich Auerbach e do próprio Antonio Candido. Cf. Spitzer (1968) e Auerbach (1976). 
parte do texto a dados verificáveis da biografia do próprio poeta, inserido no poema como um pastor cuja vida é ambientada em uma aldeia. A análise sobre as noções de representação de uma máscara ficcional criada pelo poeta, a de um pastor, demonstra o esforço de aderir aos traços da convenção da poesia pastoril árcade, mas não consegue impedir a presença de fissuras dessa máscara, por onde escorrem os traços autobiográficos de um homem nobre pertencente a um outro extrato social. A análise dessa lira específica de Gonzaga se vincula, inequivocamente, aos textos em que Candido analisa a poética de Gonzaga em Formação..., mas principalmente a dois textos do autor que integram o livro Observador literário (CANDIDO, 2008). Nessas análises anteriores, a poesia árcade é estudada traçandose um panorama geral ao mesmo tempo em que distingue alguns traços peculiares de Gonzaga. Segundo Candido, o poeta, em suas liras, mescla e combina traços de individuação e egotismo românticos com as convenções e práticas classicizantes da poesia pastoril árcade. Segundo ele, a poesia de Marília de Dirceu se filia à convenção pastoril, inclusive à temática do convite amoroso e ao topos do carpe diem anteriores ao próprio Arcadismo, sem evitar um traço peculiar da persona desse poeta, o egotismo e a emanação do lírico vincada no "biografismo" que, constantemente, faz o sujeito de enunciação/pastor se misturar ao poeta fidalgo. Nos capítulos de Formação... referentes ao poeta e ao Arcadismo, Candido acrescenta alguns aspectos fundamentais sobre Gonzaga, ao se referir à sátira das Cartas Chilenas, atribuídas ao mesmo poeta de Marília de Dirceu. O título do ensaio publicado em Na sala de aula é bem revelador de toda a figura final do poeta: trata-se de "Uma aldeia falsa", atestando que a convenção não consegue apagar os sinais que 
desvelam o seu caráter ficcional. Ressalto, porém, que, na análise, Candido não se refere à "falsidade" do pastor, mas da sua aldeia, conferindo ao poeta um traço que só poderia ser bem compreendido caso se verificasse as peculiaridades do lugar e não da voz que o enuncia. Soaria desnecessária a repetição de minha hipótese de leitura. Contudo, não custa nada dizê-la de outro modo: mais uma vez, a máscara do crítico de um poema não vedou suficientemente as frestas por onde passam sempre o historiador-teórico da literatura brasileira.

No primeiro ensaio (CANDIDO, 1987), temos um árcade que se aferra às notas da velha escola Barroca, mas funda um tema, depois convertido pelos futuros românticos brasileiros em principal matiz da sua tão propalada "cor local". O segundo antecipa uma individuação e uma subjetivação que poderiam desvirtuá-lo da convenção clássica, mas acaba por fundar um novo modo de expressão. Em ambos os casos, são recuperados e reiterados os conceitos nucleares que norteiam a leitura de Candido sobre o Arcadismo e a sua função em Formação da Literatura Brasileira. Trata-se de um período de contradições que desvelam o desejo manifesto, ou implícito, de poetas em busca de novos mecanismos de expressão que a um só tempo os singularize como vozes de um novo lugar, mas que também ateste seu engenho para integrar a tradição literária europeia, mesmo alteradas as condições de produção e circulação da literatura. Nas palavras de Candido, já teríamos então "poetas empenhados ${ }^{4}$ na produção de uma literatura brasileira", contudo ainda tributários de um "nativismo" que, mesmo não integrando um sistema

4 A noção de literatura empenhada perpassa toda a estrutura do livro de 1959. Obviamente, o escopo deste artigo impede a exposição ou discussão ampla dessa questão crucial, mas destaco como também aqui, em um livro que se pretende analítico e instrumental, essa noção se deixa antever, ainda que ela não seja explicitada. 
literário, resguarda as bases sobre a qual o "nacionalismo literário romântico" será consolidado. O terceiro ensaio "Cavalgada ambígua" trata do poema "Meu sonho", de Álvares de Azevedo. $\mathrm{O}$ autor novamente abre o ensaio constatando a relevância de um elemento formal, interno: o ritmo do poema. Trata-se de ritmo regular, em que todos os versos são eneassílabos, cuja processo de acentuação os faz anapésticos, em uma cadência e estrutura formal que remete às baladas medievais e românticas. $\mathrm{O}$ ritmo, ofegante e martelado, estrutura o possível diálogo que se dá entre um "Eu" e um "cavaleiro das trevas escuras". A análise da estrutura geral do poema não poderia deixar de apontar, segundo Candido, para o seu próprio título "Meu sonho" e para o vocabulário que remete a um universo mórbido e soturno. Os elementos internos elencados consentiriam a correlação com dados autobiográficos do poeta Álvares de Azevedo, externos, conjunção que permitiria a análise crítica psicanalítica do poema. Um vocabulário de inegável simbologia fálica, aliado ao ritmo ofegante do poema e à referência explícita ao ato de sonhar no próprio título são indícios que postulam sua interpretação como a figuração de um sonho de angústia de evidente etiologia sexual. A análise desse poema específico atualiza argumentos apresentados em "Ariel e Caliban", capítulo de Formação da literatura brasileira. Em ambos os textos, Antonio Candido destaca na poesia do adolescente Álvares de Azevedo a presença de uma orientação contraditória, que o aproxima de modelos estéticos europeus, conferindo-lhes uma feição singular e própria, ditadas por um poeta específico de um lugar específico e já outro. No caso do poema "Meu Sonho", há que se destacar ainda a sua feição dramática: trata-se de uma figuração de diálogo entre 
duas vozes que, por força da interpretação sugerida, convertemse em duas vozes divergentes de um mesmo "eu" cindido na figuração do sonho que confronta a voz do sujeito sonhador com as sombras de um "recalcado" que ele teima em não trazer à luz. Desse modo, a leitura analítica desse poema reitera algo já dito sobre o mesmo poeta, quando da avaliação de sua obra completa, presente no já referido "Ariel e Caliban". Da análise crítica de um poema chegamos, novamente, a um conjunto de pressupostos que permitem ler a poesia do poeta, de um modo geral, e além disso traçar um panorama de sua situação histórica nos quadros da Literatura Brasileira. A tensão entre particular/ local e universal, novamente, regula a leitura crítica de um único texto, apresentando a poesia de Álvares de Azevedo como parte integrante de um processo emancipatório que assimila as formas de "fora", a tradição romântica europeia, conferindo a elas uma feição singular, cada vez mais nossa e cada vez mais "de dentro". As duas vozes se confrontam no interior do sujeito/poeta, a "binomia" anjo-demônio, grotesco e sublime, constituindo duas faces de um mesmo rosto. Um sujeito cindido, tentando conciliar as vozes internas e externas e conceber de si uma unidade homogênea, mesmo que prenhe de dilemas. Um adolescente e suas sombras noturnas: nada mais local do que isso, nada mais universal do que isso, nada mais impossível de demarcar um lugar e uma temporalidade precisos do que isso.

O ensaio seguinte se ocupa de um poema de Alberto de Oliveira, atribuindo-lhe o caráter descritivotípico dos movimentos poéticos que aderem, no fim do século XIX, à chamada "arte pela arte". Destacam-se os seus traços descritivos que almejam anular as pontes entre o verbal e as suas referências usuais no 
plano das coisas. A descrição de uma tumba nos lança para o "coração do silêncio", lugar de exploração dos significantes, visando destacá-los dos sentidos usuais e de toda a sua cadeia de referências, o que resultaria no esvaziamento da palavra, visando torná-la autorreferente. Um poema, próximo daquilo que Mallarmé denominou um "inutensílio da linguagem"5, ou como conclui o próprio Antonio Candido: "O mundo natural foi elidido a favor de outro, inventado pela palavra." (CANDIDO, 1992, p. 67). E embora seja ressaltado o gosto pelo descritivismo de elementos exóticos e absolutamente dispares da realidade local, só o próprio empenho de nos vincular a essa tradição e de propor que haja aqui a viabilidade de tematizar algo que soaria estranho e pouco familiar, já denota o esboço de uma maioridade local a ponto de se julgar à altura da apropriação de modelos e até mesmo temas e procedimentos não mais vistos como estrangeiros, mas também nossos. O poema de Alberto de Oliveira poderia então ser entendido como parte integrante de uma linha evolutiva-histórica que não mais precisaria se ocupar de ter como tema um dado local, exercitando, ao contrário, um esforço de assepsia da linguagem e apagamento de seus mecanismos de integração à língua do mundo. Apresenta-se aí, portanto, um sujeito poético que se licencia a um patamar de isolamento e de incomunicabilidade similar ao que o próprio Antonio Candido em seu texto "O albatroz e o chinês" (CANDIDO, 2010), bem posterior à análise do poema de

5 Aponto aqui a similaridade que há entre a leitura de Candido para o "Fantástica", de Alberto de Oliveira, e a análise que Hugo Friedrich faz de um soneto de Mallarmé, no capítulo "Mallarmé", de seu livro Estrutura da lírica moderna (FRIEDRICH, 1982). Em ambos, desponta essa ideia de uma poesia que esvazia a linguagem de seus sentidos correntes, investindo na ideia de uma poesia "inútil" ou que resulta em uma máquina de linguagem que se constituíra como "esforços" de violar o caráter referencial e gasto da linguagem comum. 
Alberto de Oliveira presente em Na sala de aula, aponta ser uma figuração bastante presente na poesia de Baudelaire e de alguns de seus contemporâneos. Há em Alberto de Oliveira a mesma tentativa de figurar no poema "o destino do poeta em meio à turba que não o compreende". Isso só se poderia alcançar em uma situação histórica que permite divisar a existência de um campo literário, nos quais as rotinas e práticas inerentes à produção, circulação e recepção da literatura se efetivaram. Mais que isso, o poeta só poderia alçar esse "voo" de albatroz "desgracioso e com asas inúteis" por cima de um panorama que já possuísse um conjunto razoável de "marinheiros" que conseguissem manejar o barco ao mesmo tempo em que tentam capturar o pássaro. Assim, a autorreferência do poético é ela também sinal de um lugar histórico e de uma crença na autonomização da linguagem poética, que só poderia ter lugar em um país como o Brasil depois de um processo de constituição de um sistema literário que já assegurasse a presença de poetas com relativa autonomia em relação aos modos de dizer, justamente por acreditarem que havia entre nós uma comunidade, embora restrita, de leitores habilitados ao manejo do leme do poema. ${ }^{6}$

Nos dois ensaios finais, são analisados dois poemas da primeira metade do século XX: um de Manuel Bandeira, de 1936, e outro, de Murilo Mendes, publicado em livro de 1947. Embora não se declare a intenção de tomar os seis poemas analisados em Na sala de aula como paradigmáticos de estilos

6 A aproximação entre o ensaio "No coração do silêncio", presente em Na sala de aula, e o ensaio "O Albatroz e o chinês" é decorrência de uma leitura minha. Nunca foi aventada pelo próprio Antonio Candido, que no ensaio sobre Baudelaire não faz qualquer analogia com o movimento de "arte pela arte" da poesia finissecular no Brasil e a poesia baudelaireana. Contudo, julgo que muito da interpretação feita sobre "Fantástica", de Alberto de Oliveira, aponta para conclusões similares às que Candido faz ao analisar o poema de Baudelaire. E nisso consiste a aproximação que entre elas aqui faço, mesmo sem qualquer explicitação de vínculos entre elas por parte do autor. 
de época ou escolas literárias, ou, ainda, de conduzir as análises de modo a oferecer um quadro evolutivo da lírica brasileira, isso é o que parece ocorrer, como exemplificam bem, no meu entendimento, os dois últimos ensaios. ${ }^{7} \mathrm{O}$ primeiro, "Carrossel", analisa o poema "Rondó dos Cavalinhos", de Manuel Bandeira. Nele, a teoria analítica exposta por Candido no prefácio parece ganhar concretude e possibilidade de ser seguida em todo o seu rigor e precisão:

Os dois últimos ensaios, no meu entendimento, exemplificam bem essa constatação. O primeiro, "Carrossel”, analisa o poema "Rondó dos Cavalinhos", de Manuel Bandeira. Nele, a teoria analítica exposta por Candido no prefácio parece ganhar concretude e possibilidade de ser seguida em todo o seu rigor e precisão:

Com maior ou menor minúcia conforme o caso, as análises focalizam os aspectos relevantes de cada poema: às vezes a correlação dos segmentos, às vezes a função estrutural dos dados biográficos, às vezes o ritmo, a oposição dos significados, o vocabulário etc. Mas em todas elas está implícito o conceito básico de estrutura como correlação sistemática das partes, e é visível o interesse pelas tensões que a oscilação

7 A ideia de supor o Arcadismo como "primórdio" e o Modernismo "como estágio evolutivo final" da Literatura Brasileira é a linha adotada em quase todos os estudos historiográficos de Antonio Candido. Em Formação da literatura brasileira: momentos decisivos, ele concebe a literatura brasileira como "o esforço de um povo em busca da construção de uma literatura", o que se inicia com os primeiros árcades e um incipiente nativismo esboçado por eles e ganha maturidade com o Romantismo e a Independência política do Brasil. O recorte do livro, obviamente, impediria de incluir o Modernismo e qualquer outra produção literária posterior ao século XIX, já que se fecha com o capítulo referente ao ensaio "Instinto de nacionalidade", de Machado de Assis. No entanto, existe na produção de Candido uma série de textos e livros que apontam o Modernismo como o estágio evolutivo final da lei de nossa "evolução espiritual e cultural", a lei de proceder à "síntese gradativa entre as tendências localistas e universalistas”. Cf. Candido (1959, 1965). 
ou oposição criam nas palavras e entre as palavras e na estrutura, frequentemente com estratificação de significados. (CANDIDO, 1987, p. 6).

Conforme sevê, cada análise focaliza um elemento específico constitutivo de um poema, fazendo dele a chave explicativa que permite deslindar seus sentidos e as leis de organização de sua estrutura. Em cada análise se focaliza um desses ingredientes da receita: aspectos historiográficos e estéticos, no primeiro ensaio; função estrutural dos dados biográficos, no segundo; o ritmo, no terceiro; o vocabulário, no quarto, e, finalmente, nesse quinto ensaio, o emprego de todos esses recursos ao mesmo tempo, definindo a oposição entre as partes como lei organizadora da estrutura do poema de Bandeira.

O poema de Manuel Bandeira, analisado por Antonio Candido, sinaliza em seu aspecto formal que é a síntese globalizadora do que cada poema anterior oferecia. A análise de "Rondó dos cavalinhos", de A estrela da manhã, de 1936, parte de um elemento formal, uma parte do poema, o seu refrão. O dístico utilizado como estribilho apresenta, segundo Candido, uma desconexão rítmica, um verso entrecortado pela pontuação e outro verso que desliza em função da ausência dela. A tensão, mediada pela pontuação e a consequente disparidade do ritmo, é reiterada pela oposição promovida pelo emprego de dois sufixos diferentes associados à mesma palavra: "cavalinhos" e "cavalões". A flexão de grau permite antever uma inversão e uma disposição irônica que perpassará todo o poema. Os homens se brutalizam e animalizam em função do aumentativo pejorativo e os animais se personificam em função do uso de um diminutivo afetivo. Um mesmo vocábulo designa homens 
e cavalos; contudo, uma pequena alteração permite subverter a "lógica usual", conferindo ao homem um lugar de animalidade e ao animal um lugar de humanidade. A tensão decorrente de uma parte do poema, seu estribilho, é vista como elemento condensador do sentido geral dele. A parte e o todo se iluminam e se explicam, mutuamente, em um movimento de leitura circular, que convocará dados da História da primeira metade do século XX; a figuração do tema lírico-amoroso; dados biográficos e circunstanciais da vida de Bandeira e de um almoço oferecido a um amigo próximo. Tudo isto se postula ainda como elemento que demonstra como uma forma medieval, o rondó ou rondel, é atualizado pela poesia de Manuel Bandeira. Dessa forma, se, em cada um dos quatro poemas anteriormente analisados, foi possível destacar um elemento formal específico, dos tantos que se poderia empregar como recurso analítico, no de Manuel Bandeira aparentemente todos esses níveis de formalização da análise (o ritmo; a estrutura sintática; o tempo verbal; a correlação com dados autobiográficos; as questões pertinentes ao período literário e histórico de modo mais amplo; o vocabulário e os usos e abusos de uma forma literária usual) serão convertidos em recursos que se prestam à análise totalizante do objeto. Além disso, todos esses elementos aparecem aqui coordenados por um princípio geral ordenador que os unifica, a ironia. Assim, a própria configuração da análise destaca, no poema de Bandeira, um sinal da função modernista de síntese dos esforços anteriores de amalgamar recursos, de fundir fundo e forma e de conceber uma poesia nacional que sequer se precise dizer nacional, ou síntese de localismo e universalismo, por tão universal e autônoma que é. Por tão totalizante e específica, ela é então apenas poesia, Manuel Bandeira apenas poeta, para os quais só sobrariam como qualificativos adequados os de completo e único. 
O ensaio que fecha o livro propõe uma análise de poema de Murilo Mendes, de 1947. Nele, Candido não destacará elementos formais específicos, mas buscará demonstrar como a poesia de Murilo Mendes pode ser inscrita nos quadros universais da poética modernista, segundo conceitos como os de "impertinência", "choque" ou "dissonância", proposto por alguns dos mais conhecidos teóricos europeus da poética da modernidade, seguindo de perto algumas formulações propostas por Jean Cohen e Hugo Friedrich. Desse modo, aponta um estágio fulcral no complexo evolutivo da literatura brasileira. A superação da dependência cultural nos coloca em uma posição não mais de periferia em relação a um centro colonizador, mas lugar de emissão de uma visão de mundo e de uma prática de produção poética extensiva de uma longa tradição, a qual nos filiamos, antes, como dependentes, e da qual, hoje, poderíamos atuar como produtores. Poderia, aqui, desenvolver, longamente, como essa análise é tributária e engendradora da noção literária, e hoje conceitual, de Antropofagia. Os limites desse texto me forçam, contudo, a concluir que, mesmo em um livro que visa a reunir exercícios de análise literária - aparentemente despretensiosos e que se ocupam da exemplificação de técnicas analíticas para serem utilizadas em sala de aula, portanto didático -, ainda assim, a ordenação das análises, a escolha dos textos e a estruturação do livro denunciam que o pensamento historiográfico do autor está diluído, mas nunca ausente

No que se refere aos modelos analíticos instrumentalizados através de análises literárias exemplares, pode também detectarse grande parte do arcabouço teórico que Antonio Candido explicita e formaliza em $\mathbf{O}$ estudo analítico do poema. A teoria exposta no livro parece encontrar Na sala de aula como seu lugar de plena exemplificação. Cumprindo função 
complementar, a teoria se esboça em um livro e é aplicada em um caderno de "exercícios" exemplares. Desse modo é que uma noção teórica como a de estrutura é tomada de empréstimo dos estudos estruturalistas, como base teórica que, assimilada, será devolvida com nova roupagem, na qual não significará morte do sujeito/autor/poeta, mas emprego de dados biográficos quando se fizerem necessários. A História - tanto da literatura quanto das práticas sociais, culturais e econômicas (se é que nessa fundação crítica-teórica há, entre o estético e o social, uma fronteira) - interessa também, desde que esse "externo se torne interno e estruturador da obra poética, ou seja estético". Assim, na análise dos poemas, a obra de Candido avalia na poesia aquilo que também a sua teoria formula: a "lei de nossa evolução espiritual e cultural é a síntese entre tendências localistas e universalistas", e a partir do Modernismo e de sua devoração e assimilação do de fora, teremos um novo de dentro, que inclui uma poesia autônoma e específica e uma teoria crítica igualmente autônoma e específica para deslindar os sentidos uma da outra. Teoria que se funda no literário, ou um literário que se presta a legitimar o que o teórico funda, a partir dele. Noções como as de chave interpretativa; de estrutura fundada na lei da oscilação, ou da oposição; circularidade entre traço de estilo e traço de época; impertinência do poético, ou provocação do choque no leitor a partir da ruptura de uma aura: todas essas palavras de um vocabulário crítico universal se fundem e se assimilam, ou se preferir, são devoradas na boca de um fundador crítico-teórico de um modelo analítico que se ajusta aos modelos de composição estética instaurados pelo Modernismo brasileiro.

O modelo teórico-crítico-historiográfico de Antonio Candido responde a um conjunto de dilemas, a um repertório 
de perguntas e a um conjunto de produtos literários, demarcados historicamente, como aliás todo e qualquer método investigativoanalítico. O que se consegue reiterar no método dele é a coerência e coesão demarcadas em cada instância de um pensamento crítico e teórico atento a um projeto que se pode detectar em qualquer produto inscrito nele. A compreensão do que é poesia e as noções do que é compreender um poema estão, intimamente, vinculados ao que se pensa que é a literatura brasileira e atendem a um projeto que sabia o que pretendia fazer dela, e fazia. Dessa forma, a correlação entre as funções de crítico (fortemente impregnadas por sua perspectiva teórica-historiográfica), professor e político são partes integrantes de um mesmo esforço contínuo. Compreender o processo de constituição do literário no Brasil, atrelando o dinamismo do processo à feição singular de cada componente dele, só se justificava na medida em que se articula com a socialização desse conhecimento, tornando-o parte de um projeto humanizador que garante o direito inaliável à partilha desse conhecimento em "sala de aula". Não se poderia pensar em ação política mais efetiva e participante do que tornar a poesia um direito e um dever. Para uma literatura empenhada, um leitor empenhado em consolidar a circulação da poesia, o fazer do poeta e as práticas de socialização, sem as quais a poesia jamais integra ou transforma o sistema.

\section{Referências}

ARRIGUCCI JR., Davi. Movimentos de um leitor. In: D' INCAO, Maria Angla; SCARABÔTOLO, Eloisa Faria. Dentro do texto, dentro da vida. São Paulo: Cia. das Letras, 1992. 
AUERBACH, Erich. Mimesis: a representação da realidade na literatura ocidental. Tradução de George B. Sperber. São Paulo. Perspectiva. 1976.

BOSI, Alfredo. Por um historicismo renovado. Teresa. Revista de Literatura Brasileira. São Paulo: USP, 2000.

CANDIDO, Antonio. Literatura de dois gumes. In: CANDIDO, Antonio. A educação pela noite e outros ensaios. São Paulo. Ática, 1982.

CANDIDO, Antonio. Literatura e subdesenvolvimento. In: CANDIDO, Antonio. A educação pela noite e outros ensaios. São Paulo. Ática, 1982

CANDIDO, Antonio. A educação pela noite e outros estudos. São Paulo: Ática, 1982.

CANDIDO, Antonio. Formação da literatura brasileira: momentos decisivos. Belo Horizonte: Martins, 1959.

CANDIDO, Antonio. Literatura e sociedade. São Paulo: Cia ed. Nacional, 1965.

CANDIDO, Antonio. O albatroz e o chinês. In: CANDIDO, Antonio. O albatroz e o chinês. Rio de Janeiro: Ouro sobre azul, 2010. p. 13-14.

CANDIDO, Antonio. O albatroz e o chinês. Rio de Janeiro: Ouro sobre azul, 2010.

CANDIDO, Antonio. As rosas e o tempo. In: CANDIDO, Antonio. O observador literário (1959). 4. ed. Rio de Janeiro: Ouro sobre azul, 2008.

CANDIDO, Antonio. Entre pastores. In: CANDIDO, Antonio. O observador literário (1959). 4. ed. Rio de Janeiro: Ouro sobre azul, 2008. 
CANDIDO, Antonio. O observador literário (1959). 4. ed. Rio de Janeiro: Ouro sobre azul, 2008.

CANDIDO, Antonio. Dialética da malandragem. In: CANDIDO, Antonio. 4. ed. O discurso e a cidade. Rio de Janeiro: Ouro sobre azul, 2010.

CANDIDO, Antonio. O estudo analítico do poema. São Paulo: Humanitas, 1985.

CANDIDO, Antonio. Na sala de aula: caderno de análise literária. São Paulo: Ática, 1987.

CANDIDO, Antonio. Textos de intervenção. Organização, seleção e notas de Vinícius Dantas. São Paulo: 34/Duas Cidades, 2002.

FRIEDRICH, Hugo. Estrutura da lírica moderna. Tradução de Marise Curione e Dora F. da Silva. São Paulo: Duas Cidades, 1982.

SPITZER, Leo. Linguistica e história literária. 2. ed. Tradução de José Perez Riesgo. Madri: Gredos, 1968. 